\title{
APPLICATION OF RAIL TRACK GEOMETRY MEASURING TROLLEYS FOR GEOREFERENCING OF UAV IMAGES
}

\author{
V.V. Shcherbakov ${ }^{1}$, M.A. Altyntsev ${ }^{2, *}$, M.A. Altyntseva ${ }^{3}$ \\ ${ }^{1}$ Siberian Transport University, Novosibirsk, Russian Federation - vvs@stu.ru \\ ${ }^{2}$ Dep. of Engineering Geodesy and Mine Surveying, Siberian State University of Geosystems and Technologies, Novosibirsk, \\ Russian Federation-mnbcv@mail.ru \\ ${ }^{3}$ Dep. of Cartography and Geoinformation, Novosibirsk, Russian Federation - als.mm@yandex.ru
}

\author{
Commission II, WG II/2
}

KEY WORDS: Georeferencing, Photogrammetric Model, UAV, Trolleys, Rail Track, Accuracy Estimation, Ground Control Points

\begin{abstract}
:
Rail track geometry measuring trolleys are widely used in the railway industry. They can collect information about the state of rails with high accuracy. Nowadays there are a lot of trolleys. Principles of measurements in different trolleys may vary greatly. The trolleys that can use the absolute method of measuring coordinates have advantages. Coordinates of rails and rail track axis can be used as control points for georeferencing of any other surveying data. UAV images are one of these data types. In railways aerial survey using UAVs is mostly used for mapping, gathering data for creation of profiles and some other measurements. UAVs allow reducing the volume of field surveying works. The cost of UAVs is very different. Application of low-cost UAVs imposes increased requirements to distribution of control points. As distribution of control points taken from a trolley trajectory is poor, the issue of such control point application emerges. The study of opportunity to use the trolley trajectory for georeferencing of UAV images is carried out. Accuracy estimation of generating photogrammetric models and image-based point clouds using control point coordinates measured with the trolley is given. Accuracy of measuring obstruction clearances with the help of image-based point clouds is estimated.
\end{abstract}

\section{INTRODUCTION}

Unmanned Aerial Vehicles (UAV) have become very popular all over the world. Based on images acquired with UAVs orthophotoplans and three-dimensional dense point clouds can be generated. Point clouds generated from images can be used in a manner similar to ones obtained with laser scanners. Image based point clouds are often an alternative to laser scanning. Laser scanning and UAV have both advantages and disadvantages. The main advantages of using UAVs for generating point clouds are low cost and low weight of equipment with a sufficient level of accuracy for wide range of applications comparing to laser scanning technology (Rosnell, Honkavaara, 2012). UAVs can be applied in difficult access areas where laser scanners are almost impossible to use. Comparing to images derived from manned aircraft and satellites UAV can provide much better spatial and temporal resolution (Akturk, Altunel, 2019). Disadvantages of using UAVs are dependance to the illumination level and, in most cases, lower accuracy than laser scanning.

UAVs are applied for solving various tasks. Mapping, forest monitoring, searching for moving objects, crop measurements, power facilities inspection, and identification of cracks in different surfaces are only a small part of applications (Chen et al., 2020).

One of the industries where UAVs are used is the railway one. They are used for mapping, gathering data about railway track position and distance between tracks, measuring obstruction clearance, generating longitudinal and cross profiles (Flammini et al., 2016). These tasks are solved in the framework of railway as-built survey.

Image-based point clouds of railway infrastructure can be used for three-dimensional modelling of rails. 3D rail models assist to detect track deformations. They are also applied for collision testing and measuring clearance by means of simulating trains moved across the route. 3D models are often stored in up-todate databases for maintaining the railways (Jwa, Sonh, 2015). For detecting rails with high accuracy special algorithms and techniques are being developed (Sahebdivani et al., 2020). One of the latest methods for rail line extraction from UAV images was proposed by Tong et al., 2020 .

Regardless of survey parameters not all UAV models can provide an acceptable accuracy of processed data for solving a certain task. For increasing relative accuracy and, if a precise georeferencing is required, ground control points (GCPs) are used. Coordinates of GCPs are usually measured with traditional terrestrial surveying instruments such as total stations, levels and satellite receivers. GCPs are used for calculating exterior orientation parameters of images in the process of aerial triangulation (Syetiawan et al., 2020). To achieve the best level of accuracy the number of GCPs should be increased. Camera should be properly calibrated and distribution of GCPs has to be sufficient as well. A lot of studies concerning determining the number of control points and the scheme of their placement have been carried out. The necessary number of GCPs for exterior orientation is described in many photogrammetric books such as Schenk, 2005. Control points should be regularly distributed within a surveyed area and at the edges of it (Martínez-Carricondo et al., 2018). The

\footnotetext{
Corresponding author
} 
disadvantage of using GCPs is the necessity of additional measurements with terrestrial surveying equipment that take a lot of time and increases costs of a surveying process. Difficulties with placement GCPs can also occur if a surveying area is inaccessible.

The alternative method of UAV image orientation and reconstruction of $3 \mathrm{D}$ models is direct georeferencing. This method allows reconstructing precise $3 \mathrm{D}$ models with UAV images without control points. It is possible to determine precise UAV camera position at the time of each capture by means of using on-board satellite receivers in real time kinematic (RTK) or network real time kinematic (NRTK) modes and to measure UAV tilts with the help of on-board Inertial Measurement Unit (IMU). Precise exterior orientation parameters for each image are computed as a result of processing gathered data (Taddia et al., 2019). Direct georeferencing method allows producing image-based point clouds faster and more accurately than aerial triangulation. The number of control points can be as minimal as possible.

Taddia et al., 2019 conducted a study about accuracy estimation of point clouds generated on the basis of images acquired from DJI Phantom 4 RTK launched in 2018. This UAV can calculate precise exterior orientation parameters of images with direct georeferencing method. There were compared accuracies of point clouds generated without GCPs, with one GCP located at the centre of surveying area or at its edge and with several regularly distributed control points. For each case the processing was carried out twice. Firstly, source camera calibration parameters from Exif information of image files were used. Then camera calibration parameters were calculated during a self-calibration process. It was revealed that 1 control point is enough to reach high accuracy of georeferenced point cloud generated on the basis of DJI Phantom 4 RTK images.

DJI Phantom 4 RTK is a rather expensive UAV. Due to this a lot of low-cost UAVs that impose increased requirements on creating vertical and horizontal control survey network are applied. DJI Phantom 4 PRO launched in 2016 is one of lowcost UAVs. It may require a large number of regularly distributed GCPs for generating precise point clouds (COPTRZ, 2018).

Measuring GCP coordinates is a quite time-consuming task. It is especially important when low-cost UAVs are used. Shortening time of measuring GCP coordinates is always a task of current importance. To speed up this process not only traditional surveying instruments can be used. Depending on the surveying area, necessary accuracy, final production type, other surveying instruments and data sources can be applied. In railway industry these are rail track geometry measuring trolleys.

\section{APPLICATION OF RAIL TRACK GEOMETRY MEASURING TROLLEYS}

Rail track geometry measuring trolleys are being developed for accurate determination of the track quality both in the construction and the regular maintenance stage. They can define absolute track axis position and geometric parameters of rails. Absolute position includes track axis coordinates. Geometric parameters of rails are alignment, longitudinal level, gauge, cross level and twist (The British Standards Institution, 2019). There are different accuracy requirements concerning absolute rail track position and its geometric parameters. They can differ 10 or more times. For example, if absolute position is allowed determining with error of 1-3 cm, geometric parameters - 1-2 mm (Shcherbakov, 2017). Besides these accuracy requirements, another issue for rail track surveying is time efficiency. Due to high traffic, time available for using rail track geometry measuring trolleys is limited.

A lol of rail track geometry measuring trolley models are applied all over the world. Depending on their capabilities they can be divided into relative and absolute trolleys. Relative trolleys usually determine internal geometric parameters and provide relative measurement information by means of using such methods as applying inertial sensors, versine and laser alignment methods. Absolute trolleys measures both internal geometric parameters and rail track axis coordinates (Chen, 2018).

One of the most advanced trolleys is a hardware and software suite Profile-M, which is widely used in railways of Russia (Figure 1). Profile-M is an absolute trolley. As opposed to many other trolleys this one does not require creating control survey network. Profile-M includes satellite equipment with two antennas operating in synchronized and differential measurement mode of absolute and relative position. These two antennas determine the spatial orientation of the trolley axes and the motion vector in two planes. Such approach allows excluding application of expensive inertial sensors, whose operation requires calibration and adjustment both in preparation for surveying and in the process of full-scale measurements (Shcherbakov, 2017). While the trolley is moved by an operator, trajectory is recorded. Absolute coordinates of railway axis and rail heads are the results of measurements. All geometric parameters of rail tracks can be calculated.

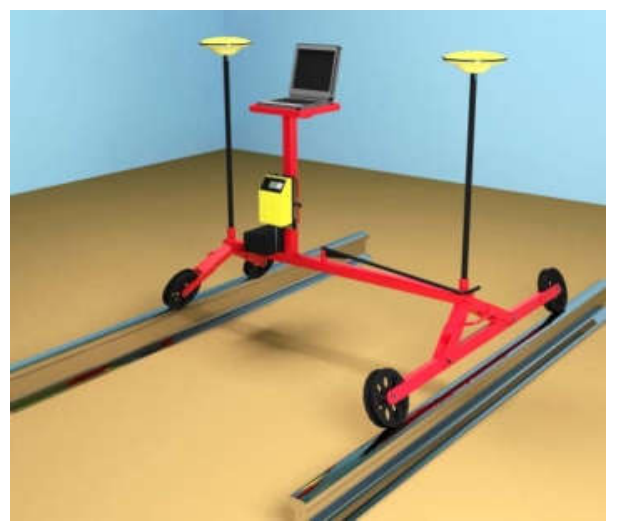

Figure 1. Hardware and software suite Profile-M

As a rule, the Profile-M trolley is also used for creating scale plans of railway stations and station-to-station blocks. These plans can have different scale factors along the $\mathrm{X}$ and $\mathrm{Y}$ axis. Requirements for creating such plans are presented in JCS "Russian Railways", 2008. The main essence of creating scale plans with the Profile-M trolley is that an operator gives specific names to rail track axis points, that are located nearly the railway objects: marking pegs, insulated joints, traffic lights, adjustable stops, supporting structures, etc. Saving these points occurs at the moments of stops. Exact trolley stop places are not marked between rails with the help of reference stakes, paint or other methods either. Railway object positions are calculated with measuring obstruction clearances. It can be done with a tape or other surveying methods. It is clear that there are some errors in determination of object positions since these positions are measured with displacement to rail track axis. It depends on the operator's viewpoint. 
Rail track axis points saved at nearly the railway objects can be used for georeferencing of cross profiles as well. Cross profiles are usually created with terrestrial surveying methods. A UAV survey allows replacing labour-consuming terrestrial methods. UAV data can also be used for measuring obstruction clearances.

Thus, combination of data acquired with the Profile-M trolley and UAVs allows solving all tasks of railway as-built survey. As the Profile-M trolley measures coordinates of rail track axis, they can be applied for georeferencing of image-based point clouds generated from low-cost UAV. In this case particularities of control point distribution should be taken into account. GCPs acquired on rail track axis do not correspond to the rule of their placement at surveying area edges. They are located at the center, along the direction of flight. GCP distribution is poor. If rail track axis is almost a straight line, image-based point clouds can be generated with high errors. Point clouds can have a tilt around this centerline. The technique of approximate measuring GCP coordinates with displacement affects the point cloud tilt as well. This issue is particularly urgent when coordinates of only one railway track within a station-to-station block are measured with the trolley. This is the frequent situation. Only one track within a block is usually repaired for a short period of time and measurement of geometry parameters of an adjacent railway track is not required. When the trolley is used for measuring two adjacent railway tracks the described issue does not take place. In this case GCP distribution is better and closer to one done for a railway corridor in Mian et al., 2016.

Application of the Profile-M trolley and low-cost UAVs allows not using other surveying instruments for all as-built survey stages. Nevertheless, it should be studied how positions of control points acquired with the Profile-M trolley affect the image-based point cloud accuracy. For high-quality study results it is necessary to use the trolley data for 2 adjacent railway tracks. To check the relative accuracy of image-based point clouds some measurement carried out with other surveying methods should be done.

\section{DATA ACQUISITION AND PROCESSING}

The survey was carried out in Kemerovo oblast between railway stations Tutalskaya and Litvinovo. A station-to-station block was surveyed with the Profile-M rail track geometry measuring trolley and UAV DJI Phantom 4 PRO. The flight was carried out in 2 strips: in forward and backward directions.

The main task of the survey was to estimate the track quality after the repairment of both tracks. The length of the surveying area was $22 \mathrm{~km}$. However, the area with the length of $4400 \mathrm{~m}$ was chosen for the study This area consisted of 1 straight section and 2 turns. DJI Phantom 4 PRO was equipped with a standard camera having a sensor of 20 megapixels. The flight height was $30 \mathrm{~m}$. Such a low height was chosen for obstruction clearances to be measured with the highest accuracy. The camera was not pre-calibrated. The parameters were calculated when processing UAV images with using all GCPs. Calibration parameters could not be calculated accurately due to particularities of GCP distribution and their placing. They were recalculated for each test.

Agisoft Metashape was chosen for processing UAV images. To estimate how quantity of control points and their distribution influence the accuracy of image georeferencing, several photogrammetric models were generated. To better demonstrate poor GCP distribution several photogrammetric models were generated both for the whole surveying area of $4400 \mathrm{~m}$ and for its straight part of $2000 \mathrm{~m}$ (Figure 2).

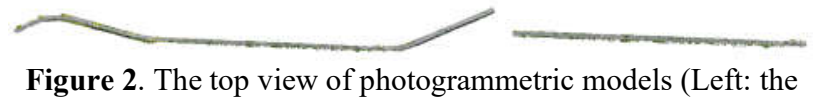

whole surveying area, Right: straight part of the surveying area)

When generating photogrammetric models different strategies concerning GCP distribution were used. Control points could be used along both adjacent rail track axis or only along one rail track axis. The distance between pairs of control points was 100 $\mathrm{m}$. It is the distance between marking pegs located along all railways. For the study the distance of $200 \mathrm{~m}$ was also chosen once. If GCPs were taken along one rail track axis, some GCPs could also be used from adjacent track when generating other photogrammetric models. Examples of placing GCPs are shown in Figures 3-5 using a photogrammetric model, a dense point cloud, and an orthothotoplan. The average distance between control points placed on the axis of adjacent railway tracks is $4.5 \mathrm{~m}$.

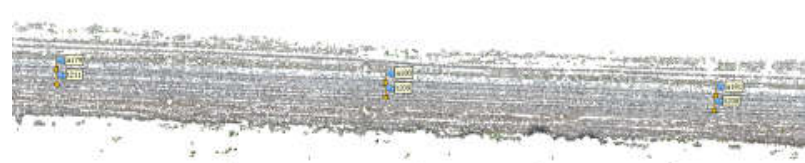

Figure 3. A fragment of the photogrammetric model with control points placed by pairs every $200 \mathrm{~m}$

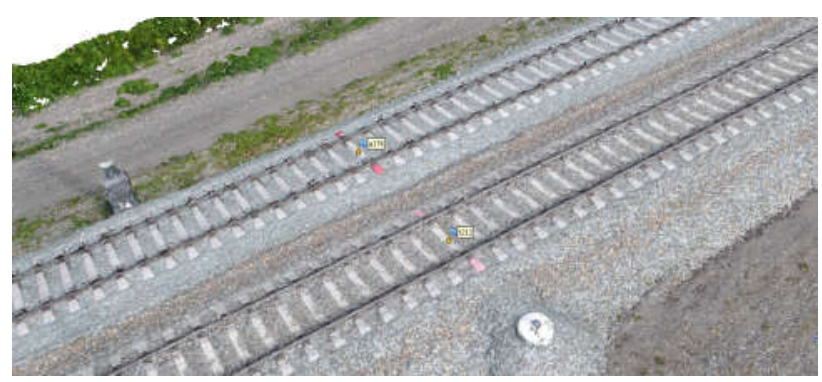

Figure 4. A fragment of a dense point cloud with control points placed by pairs

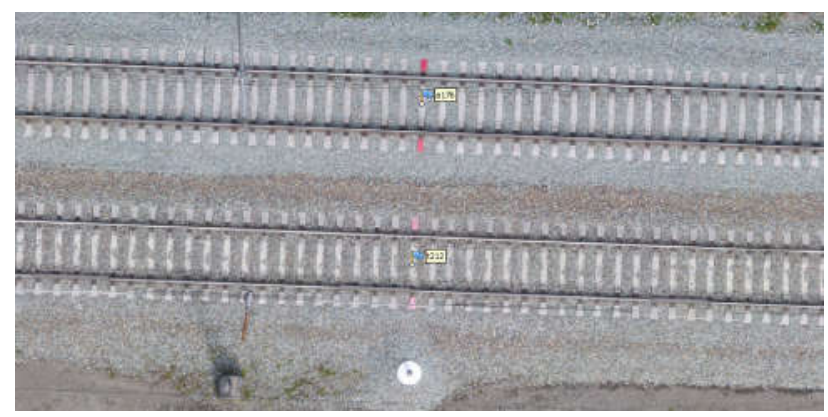

Figure 5. A fragment of an orthophotoplan with control points placed by pairs

It was also necessary to solve the issue of determining exact position of GCPs. Control points measured with the Profile-M trolley are located in the air. Their vertical positions are computed as average height between heads of right and left rails. When generating photogrammetric models control points are placed on the ground. For accurate exterior orientation of photogrammetric models, the height of rail heads above the ground between rails should be known at each position. The 
Profile-M trolley does not measure this height. Nevertheless, it is possible to calculate heights more accurately in case of placement control points on the center of rail sleepers in the cross direction. In the longitudinal direction control points were placed as close as possible to the perpendicular from railway objects to the rail track axis. The type of rails and sleepers should also be known. R65 rails are used in Russia for the majority of railways. The average height of rail heads above the center of sleepers was $24 \mathrm{~cm}$ in the studied surveying area. Measurements were checked in some places. The average height was subtracted from elevations of control points. Such approach made it possible to avoid additional errors in elevations by more than $2 \mathrm{~cm}$.

To determine how GCP distribution affects accuracy of imagebased point cloud, 22 models were generated. The initial data sets used for generation of photogrammetric models are shown in Table 1. The index of the first rail track - «a», whereas the second one $-\langle t\rangle$. The first rail track is located to the north. The photogrammetric models 1-4 and 13-16 were obtained with using control points from the single rail track. The other models were generated with using control points from both rail tracks. For example, it is specified in the Table 1 that for the model 11. 44 control points were used from the rail axis «a» and 7 ones from the rail axis «t». The number of check points for this model is 37 taken from the rail axis «t». The examples of GCP placement are shown in Figure 6. Control points taken from the rail axis $« t »$ are marked with red lines.

\begin{tabular}{|c|c|c|c|c|c|}
\hline & № & $\begin{array}{l}\text { Number } \\
\text { of } \\
\text { control } \\
\text { points }\end{array}$ & $\begin{array}{l}\text { Number } \\
\text { of check } \\
\text { points }\end{array}$ & $\begin{array}{l}\text { Distance } \\
\text { between } \\
\text { pairs of } \\
\text { control } \\
\text { points } \\
\text { along a } \\
\text { rail } \\
\text { track }\end{array}$ & $\begin{array}{l}\text { Distance } \\
\text { between } \\
\text { pairs of } \\
\text { check } \\
\text { points } \\
\text { along a } \\
\text { rail } \\
\text { track }\end{array}$ \\
\hline \multirow{12}{*}{$\begin{array}{c}\text { The } \\
\text { whole } \\
\text { area }\end{array}$} & 1 & $22 a$ & $22 a$ & $200 \mathrm{~m}$ & $200 \mathrm{~m}$ \\
\hline & 2 & $44 a$ & 0 & $100 \mathrm{~m}$ & - \\
\hline & 3 & $22 t$ & $22 t$ & $200 \mathrm{~m}$ & $200 \mathrm{~m}$ \\
\hline & 4 & $44 t$ & 0 & $100 \mathrm{~m}$ & - \\
\hline & 5 & $22 a+22 t$ & $22 a+22 t$ & $200 \mathrm{~m}$ & $200 \mathrm{~m}$ \\
\hline & 6 & $44 \mathrm{a}+44 \mathrm{t}$ & 0 & $100 \mathrm{~m}$ & - \\
\hline & 7 & $44 a+1 t$ & $43 \mathrm{t}$ & $100 \mathrm{~m}$ & - \\
\hline & 8 & $44 t+1 a$ & $43 a$ & $100 \mathrm{~m}$ & - \\
\hline & 9 & $44 a+2 t$ & $42 t$ & $100 \mathrm{~m}$ & - \\
\hline & 10 & $44 t+2 a$ & $42 a$ & $100 \mathrm{~m}$ & - \\
\hline & 11 & $44 a+7 t$ & $37 t$ & $100 \mathrm{~m}$ & - \\
\hline & 12 & $44 t+7 a$ & $37 \mathbf{a}$ & $100 \mathrm{~m}$ & - \\
\hline \multirow{10}{*}{$\begin{array}{c}\text { Strai- } \\
\text { ght } \\
\text { part of } \\
\text { the } \\
\text { area }\end{array}$} & 13 & $11 \mathrm{a}$ & $10 \mathrm{a}$ & $200 \mathrm{~m}$ & $200 \mathrm{~m}$ \\
\hline & 14 & $21 \mathrm{a}$ & 0 & $100 \mathrm{~m}$ & - \\
\hline & 15 & $11 \mathrm{t}$ & $10 \mathrm{t}$ & $200 \mathrm{~m}$ & $200 \mathrm{~m}$ \\
\hline & 16 & $21 \mathrm{t}$ & 0 & $100 \mathrm{~m}$ & - \\
\hline & 17 & $11 a+10 t$ & $10 a+11 t$ & $200 \mathrm{~m}$ & $200 \mathrm{~m}$ \\
\hline & 18 & $21 a+21 t$ & 0 & $100 \mathrm{~m}$ & - \\
\hline & 19 & $21 a+1 t$ & $20 \mathrm{t}$ & $100 \mathrm{~m}$ & - \\
\hline & 20 & $21 t+1 a$ & $20 \mathrm{a}$ & $100 \mathrm{~m}$ & - \\
\hline & 21 & $21 a+2 t$ & $19 t$ & $100 \mathrm{~m}$ & - \\
\hline & 22 & $21 t+2 a$ & $19 a$ & $100 \mathrm{~m}$ & - \\
\hline
\end{tabular}

Table 1. The initial data sets used for generation of photogrammetric models

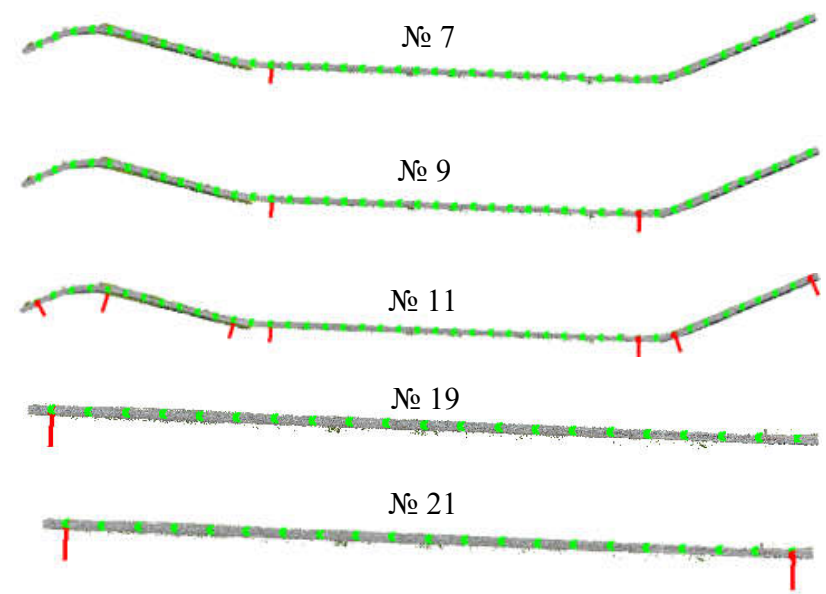

Figure 6. Schemes of placing control points for generating photogrammetric models $7,9,11,19,21$

Accuracy estimation of photogrammetric model generation is presented in Tables 2-4. When analyzing the whole surveying area, the least errors were received for model 3 . When analyzing the straight area part, they were received for model 13. It can be explained by the fact that control points were only located along single rail axis and the distance between them was increased to $200 \mathrm{~m}$. The errors using check points for these models are not high either. However, GCP distribution is poor because of their placing along a single line. It is necessary to check errors away from the rail axis. For this reason some cross sections were created. Figures 7 and 8 demonstrate cross sections for models $4,6,15$. Models № 4,15 have a tilt relatively to the rail axis «t» because of using control points only along this axis. Model 6 was generated with using all control points for both rails every $100 \mathrm{~m}$. It is obvious, that model 6 is leveled much better. The conclusion about necessity of using control points on both rail track axis can be done. The tilt of model 4 is lower than the one of model 15 because model 4 is obtained for the whole surveying area where there were 3 turns. GCP distribution a bit differs from the straight line. To estimate the value of the tilt additional check points were placed away from the rail track axis «a» at the distance of $8 \mathrm{~m}$. The number of additional check points was 44 and the distance between them was $100 \mathrm{~m}$. Only vertical positional accuracy (Table 5) was measured.

Next, it should be decided how many control points are needed to use on adjacent rail track axis. The less the number of GCPs is, the faster the surveying can be carried out. From Tables 2-5 it is seen that the least errors, when analyzing the whole area, were computed for models 11,12 . It means that control points should be used on adjacent rail track axis at the beginning and at the end of its straight part. When analyzing the straight part of the area very similar errors were computed for models 17, 1922. It can be concluded that one control point on the adjacent rail track is enough for generating an accurate model if the direction of a rail track is close to a straight line (Figure 9). The maximum error of $0.302 \mathrm{~cm}$ in a vertical position obtained for the check point of model 8 is connected with the lack of control points in the adjacent rail track and the fact that this check point is located at the rail track turn. 


\begin{tabular}{|c|c|c|c|c|c|c|}
\hline \multirow{2}{*}{$№$} & \multicolumn{3}{|c|}{ Control points } & \multicolumn{3}{c|}{ Check points } \\
\cline { 2 - 7 } & $\mathrm{X}, \mathrm{m}$ & $\mathrm{Y}, \mathrm{m}$ & $\mathrm{Z}, \mathrm{m}$ & $\mathrm{X}, \mathrm{m}$ & $\mathrm{Y}, \mathrm{m}$ & $\mathrm{Z}, \mathrm{m}$ \\
\hline 1 & 0.006 & 0.006 & 0.006 & 0.060 & 0.040 & 0.068 \\
\hline 2 & 0.022 & 0.015 & 0.007 & - & - & - \\
\hline 3 & $\mathbf{0 . 0 0 4}$ & $\mathbf{0 . 0 0 6}$ & $\mathbf{0 . 0 0 6}$ & $\mathbf{0 . 0 4 1}$ & $\mathbf{0 . 0 3 2}$ & $\mathbf{0 . 0 6 3}$ \\
\hline 4 & 0.012 & 0.011 & 0.007 & - & - & - \\
\hline 5 & 0.038 & 0.019 & 0.018 & 0.067 & 0.036 & 0.057 \\
\hline 6 & 0.049 & 0.022 & 0.019 & - & - & - \\
\hline 7 & 0.021 & 0.014 & 0.007 & 0.099 & 0.040 & 0.077 \\
\hline 8 & 0.016 & 0.018 & 0.011 & 0.097 & 0.041 & 0.080 \\
\hline 9 & 0.022 & 0.014 & 0.008 & 0.098 & 0.041 & 0.071 \\
\hline 10 & 0.017 & 0.018 & 0.011 & 0.099 & 0.042 & 0.071 \\
\hline 11 & $\mathbf{0 . 0 3 1}$ & $\mathbf{0 . 0 1 6}$ & $\mathbf{0 . 0 1 2}$ & $\mathbf{0 . 0 9 3}$ & $\mathbf{0 . 0 4 1}$ & $\mathbf{0 . 0 4 5}$ \\
\hline 12 & $\mathbf{0 . 0 2 4}$ & $\mathbf{0 . 0 1 4}$ & $\mathbf{0 . 0 1 2}$ & $\mathbf{0 . 0 9 5}$ & $\mathbf{0 . 0 4 0}$ & $\mathbf{0 . 0 4 7}$ \\
\hline 13 & 0.002 & 0.005 & 0.002 & 0.036 & 0.035 & 0.052 \\
\hline 14 & 0.009 & 0.009 & 0.005 & - & - & - \\
\hline 15 & 0.005 & 0.006 & 0.002 & 0.025 & 0.020 & 0.073 \\
\hline 16 & 0.005 & 0.007 & 0.007 & - & - & - \\
\hline 17 & $\mathbf{0 . 0 3 4}$ & $\mathbf{0 . 0 1 4}$ & $\mathbf{0 . 0 1 1}$ & $\mathbf{0 . 0 6 5}$ & $\mathbf{0 . 0 2 7}$ & $\mathbf{0 . 0 6 3}$ \\
\hline 18 & 0.044 & 0.014 & 0.016 & - & - & - \\
\hline 19 & $\mathbf{0 . 0 0 9}$ & $\mathbf{0 . 0 0 9}$ & $\mathbf{0 . 0 0 5}$ & $\mathbf{0 . 1 0 0}$ & $\mathbf{0 . 0 3 0}$ & $\mathbf{0 . 0 3 5}$ \\
\hline 20 & $\mathbf{0 . 0 0 5}$ & $\mathbf{0 . 0 0 6}$ & $\mathbf{0 . 0 0 4}$ & $\mathbf{0 . 1 0 3}$ & $\mathbf{0 . 0 2 7}$ & $\mathbf{0 . 0 5 5}$ \\
\hline 21 & $\mathbf{0 . 0 1 4}$ & $\mathbf{0 . 0 0 9}$ & $\mathbf{0 . 0 0 4}$ & $\mathbf{0 . 1 0 0}$ & $\mathbf{0 . 0 3 1}$ & $\mathbf{0 . 0 4 9}$ \\
\hline 22 & $\mathbf{0 . 0 1 0}$ & $\mathbf{0 . 0 0 7}$ & $\mathbf{0 . 0 0 4}$ & $\mathbf{0 . 1 0 3}$ & $\mathbf{0 . 0 2 8}$ & $\mathbf{0 . 0 6 2}$ \\
\hline
\end{tabular}

Table 2. Mean errors of generated photogrammetric models

\begin{tabular}{|c|c|c|c|c|c|c|}
\hline \multirow{2}{*}{$№$} & \multicolumn{3}{|c|}{ Control points } & \multicolumn{3}{c|}{ Check points } \\
\cline { 2 - 7 } & $\mathrm{X}, \mathrm{m}$ & $\mathrm{Y}, \mathrm{m}$ & $\mathrm{Z}, \mathrm{m}$ & $\mathrm{X}, \mathrm{m}$ & $\mathrm{Y}, \mathrm{m}$ & $\mathrm{Z}, \mathrm{m}$ \\
\hline 1 & 0.009 & 0.008 & 0.007 & 0.086 & 0.052 & 0.091 \\
\hline 2 & 0.032 & 0.020 & 0.010 & - & - & - \\
\hline 3 & $\mathbf{0 . 0 0 6}$ & $\mathbf{0 . 0 0 7}$ & $\mathbf{0 . 0 0 8}$ & $\mathbf{0 . 0 6 6}$ & $\mathbf{0 . 0 4 3}$ & $\mathbf{0 . 0 7 8}$ \\
\hline 4 & 0.023 & 0.017 & 0.009 & - & - & - \\
\hline 5 & 0.047 & 0.026 & 0.022 & 0.095 & 0.048 & 0.074 \\
\hline 6 & 0.062 & 0.030 & 0.023 & - & - & - \\
\hline 7 & 0.030 & 0.019 & 0.010 & 0.117 & 0.051 & 0.102 \\
\hline 8 & 0.033 & 0.049 & 0.028 & 0.123 & 0.056 & 0.111 \\
\hline 9 & 0.032 & 0.019 & 0.011 & 0.116 & 0.052 & 0.093 \\
\hline 10 & 0.034 & 0.048 & 0.027 & 0.122 & 0.056 & 0.094 \\
\hline 11 & $\mathbf{0 . 0 4 5}$ & $\mathbf{0 . 0 2 2}$ & $\mathbf{0 . 0 1 8}$ & $\mathbf{0 . 1 0 8}$ & $\mathbf{0 . 0 5 1}$ & $\mathbf{0 . 0 5 5}$ \\
\hline 12 & $\mathbf{0 . 0 3 8}$ & $\mathbf{0 . 0 2 0}$ & $\mathbf{0 . 0 1 8}$ & $\mathbf{0 . 1 1 9}$ & $\mathbf{0 . 0 5 4}$ & $\mathbf{0 . 0 5 8}$ \\
\hline 13 & 0.003 & 0.006 & 0.002 & 0.048 & 0.043 & 0.074 \\
\hline 14 & 0.014 & 0.012 & 0.007 & - & - & - \\
\hline 15 & 0.005 & 0.007 & 0.003 & 0.032 & 0.029 & 0.084 \\
\hline 16 & 0.006 & 0.010 & 0.008 & - & - & - \\
\hline 17 & $\mathbf{0 . 0 3 9}$ & $\mathbf{0 . 0 2 1}$ & $\mathbf{0 . 0 1 4}$ & $\mathbf{0 . 0 7 8}$ & $\mathbf{0 . 0 3 3}$ & $\mathbf{0 . 0 7 0}$ \\
\hline 18 & 0.052 & 0.020 & 0.018 & - & - & - \\
\hline 19 & $\mathbf{0 . 0 1 3}$ & $\mathbf{0 . 0 1 1}$ & $\mathbf{0 . 0 0 7}$ & $\mathbf{0 . 1 0 8}$ & $\mathbf{0 . 0 3 9}$ & $\mathbf{0 . 0 4 2}$ \\
\hline 20 & $\mathbf{0 . 0 0 7}$ & $\mathbf{0 . 0 0 9}$ & $\mathbf{0 . 0 0 5}$ & $\mathbf{0 . 1 1 2}$ & $\mathbf{0 . 0 3 8}$ & $\mathbf{0 . 0 6 6}$ \\
\hline 21 & $\mathbf{0 . 0 2 1}$ & $\mathbf{0 . 0 1 1}$ & $\mathbf{0 . 0 0 5}$ & $\mathbf{0 . 1 0 9}$ & $\mathbf{0 . 0 4 0}$ & $\mathbf{0 . 0 6 1}$ \\
\hline 22 & $\mathbf{0 . 0 1 8}$ & $\mathbf{0 . 0 0 9}$ & $\mathbf{0 . 0 0 5}$ & $\mathbf{0 . 1 1 3}$ & $\mathbf{0 . 0 4 0}$ & $\mathbf{0 . 0 7 1}$ \\
\hline
\end{tabular}

Table 3. RMS errors of generated photogrammetric models

\begin{tabular}{|c|c|c|c|c|c|c|}
\hline \multirow{2}{*}{$№$} & \multicolumn{3}{|c|}{ Control points } & \multicolumn{3}{c|}{ Check points } \\
\cline { 2 - 7 } & $\mathrm{X}, \mathrm{m}$ & $\mathrm{Y}, \mathrm{m}$ & $\mathrm{Z}, \mathrm{m}$ & $\mathrm{X}, \mathrm{m}$ & $\mathrm{Y}, \mathrm{m}$ & $\mathrm{Z}, \mathrm{m}$ \\
\hline 1 & 0.023 & 0.015 & 0.016 & 0.231 & 0.120 & 0.212 \\
\hline 2 & 0.104 & 0.061 & 0.031 & - & - & - \\
\hline 3 & $\mathbf{0 . 0 1 5}$ & $\mathbf{0 . 0 1 5}$ & $\mathbf{0 . 0 1 8}$ & $\mathbf{0 . 2 0 5}$ & $\mathbf{0 . 1 0 2}$ & $\mathbf{0 . 1 5 4}$ \\
\hline 4 & 0.079 & 0.055 & 0.022 & - & - & - \\
\hline 5 & 0.112 & 0.059 & 0.046 & 0.268 & 0.138 & 0.234 \\
\hline 6 & 0.189 & 0.077 & 0.068 & - & - & - \\
\hline 7 & 0.084 & 0.050 & 0.029 & 0.251 & 0.125 & 0.248 \\
\hline 8 & 0.160 & 0.310 & 0.174 & 0.334 & 0.121 & 0.302 \\
\hline 9 & 0.084 & 0.050 & 0.032 & 0.243 & 0.125 & 0.226 \\
\hline 10 & 0.160 & 0.301 & 0.168 & 0.321 & 0.121 & 0.268 \\
\hline 11 & $\mathbf{0 . 1 4 7}$ & $\mathbf{0 . 0 5 3}$ & $\mathbf{0 . 0 5 3}$ & $\mathbf{0 . 2 1 4}$ & $\mathbf{0 . 1 2 7}$ & $\mathbf{0 . 1 2 7}$ \\
\hline 12 & $\mathbf{0 . 1 2 7}$ & $\mathbf{0 . 0 5 8}$ & $\mathbf{0 . 0 5 9}$ & $\mathbf{0 . 2 9 3}$ & $\mathbf{0 . 1 2 1}$ & $\mathbf{0 . 1 8 3}$ \\
\hline 13 & 0.006 & 0.013 & 0.005 & 0.109 & 0.093 & 0.186 \\
\hline 14 & 0.048 & 0.023 & 0.023 & - & - & - \\
\hline 15 & 0.011 & 0.011 & 0.007 & 0.068 & 0.071 & 0.135 \\
\hline 16 & 0.018 & 0.030 & 0.017 & - & - & - \\
\hline 17 & $\mathbf{0 . 0 7 5}$ & $\mathbf{0 . 0 5 4}$ & $\mathbf{0 . 0 3 1}$ & $\mathbf{0 . 1 4 7}$ & $\mathbf{0 . 0 6 4}$ & $\mathbf{0 . 1 3 7}$ \\
\hline 18 & 0.097 & 0.058 & 0.037 & - & - & - \\
\hline 19 & $\mathbf{0 . 0 4 1}$ & $\mathbf{0 . 0 2 7}$ & $\mathbf{0 . 0 1 9}$ & $\mathbf{0 . 1 6 5}$ & $\mathbf{0 . 0 9 7}$ & $\mathbf{0 . 0 7 0}$ \\
\hline 20 & $\mathbf{0 . 0 1 5}$ & $\mathbf{0 . 0 2 4}$ & $\mathbf{0 . 0 1 0}$ & $\mathbf{0 . 1 7 2}$ & $\mathbf{0 . 1 0 6}$ & $\mathbf{0 . 1 1 2}$ \\
\hline 21 & $\mathbf{0 . 0 5 0}$ & $\mathbf{0 . 0 2 7}$ & $\mathbf{0 . 0 1 1}$ & $\mathbf{0 . 1 6 4}$ & $\mathbf{0 . 0 9 6}$ & $\mathbf{0 . 0 9 5}$ \\
\hline 22 & $\mathbf{0 . 0 5 0}$ & $\mathbf{0 . 0 2 3}$ & $\mathbf{0 . 0 1 0}$ & $\mathbf{0 . 1 7 3}$ & $\mathbf{0 . 1 0 6}$ & $\mathbf{0 . 1 1 6}$ \\
\hline
\end{tabular}

Table 4. Maximum errors of generated photogrammetric models

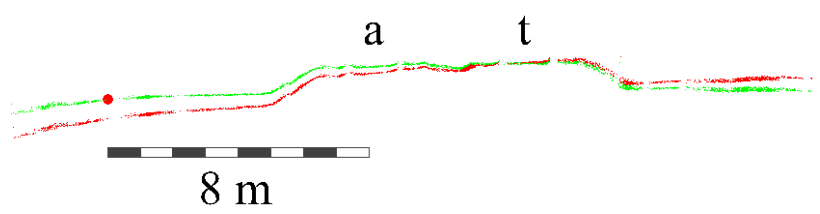

Figure 7. Cross sections for photogrammetric models 6 (green) and 15 (red)

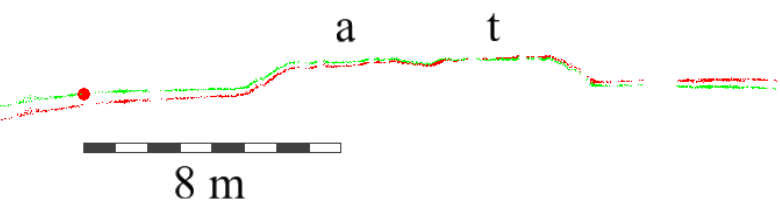

Figure 8. Cross sections for photogrammetric models 6 (green) and 4 (red)

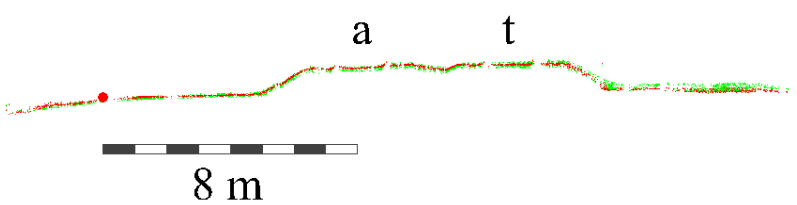

Figure 9. Cross sections for photogrammetric models 6 (green) and 19 (red) 


\begin{tabular}{|c|c|c|c|}
\hline \multirow{2}{*}{$\begin{array}{c}\text { The } \\
\text { photogrammetric } \\
\text { model number }\end{array}$} & \multicolumn{3}{|c|}{ Vertical positional accuracy estimation } \\
\hline & $\begin{array}{c}\text { Mean } \\
\text { errors, } \mathrm{m}\end{array}$ & $\begin{array}{c}\text { RMS } \\
\text { errors, } \mathrm{m}\end{array}$ & $\begin{array}{c}\text { Maximum } \\
\text { errors, } m\end{array}$ \\
\hline 1 & 0.125 & 0.153 & 0.322 \\
\hline 2 & 0.103 & 0.129 & 0.206 \\
\hline 3 & 0.234 & 0.291 & 0.529 \\
\hline 4 & 0.228 & 0.295 & 0.504 \\
\hline 5 & 0.026 & 0.035 & 0.083 \\
\hline 7 & 0.123 & 0.150 & 0.233 \\
\hline 8 & 0.239 & 0.303 & 0.477 \\
\hline 9 & 0.085 & 0.105 & 0.165 \\
\hline 10 & 0.166 & 0.217 & 0.371 \\
\hline 11 & 0.031 & 0.039 & 0.067 \\
\hline 12 & 0.033 & 0.039 & 0.059 \\
\hline 13 & 0.174 & 0.196 & 0.216 \\
\hline 14 & 0.171 & 0.186 & 0.203 \\
\hline 15 & 0.596 & 0.610 & 0.622 \\
\hline 16 & 0.409 & 0.417 & 0.419 \\
\hline 17 & 0.010 & 0.014 & 0.020 \\
\hline 19 & 0.022 & 0.026 & 0.033 \\
\hline 20 & 0.019 & 0.024 & 0.030 \\
\hline 21 & 0.017 & 0.022 & 0.025 \\
\hline 22 & 0.020 & 0.022 & 0.023 \\
\hline
\end{tabular}

Table 5. Vertical positional accuracy estimation of generated photogrammetric models using check points located at $8 \mathrm{~m}$ away from the rail rack axis «a»

Photogrammetric model 11 was used for generating dense point cloud after that. It was necessary to determine if the imagebased point cloud is appropriate for measuring obstruction clearances and distances between rail tracks. Obstruction clearances measured in the point cloud were compared with measurements carried out with a total station. Based on the comparison of these measurement horizontal positional accuracy (Table 6) was estimated. The results of accuracy estimation showed that image-based point cloud can be used for measuring obstruction clearance because errors did not exceed tolerances. In compliance with JCS "Russian Railways", 2013 accuracy of measuring distances in the railway must not exceed $3 \mathrm{~cm}$. High accuracy was reached due to low flight altitude as well.

\begin{tabular}{|c|c|c|}
\hline $\begin{array}{c}\text { Mean error, } \\
\mathrm{m}\end{array}$ & $\begin{array}{c}\text { RMS error, } \\
\mathrm{m}\end{array}$ & $\begin{array}{c}\text { Maximum } \\
\text { error, } \mathrm{m}\end{array}$ \\
\hline 0.018 & 0.024 & 0.029 \\
\hline
\end{tabular}

Table 6. Horizontal positional accuracy estimation of measuring obstruction clearance

The image-based point cloud was also used for creating cross profiles. As the surveying was carried out after the repairment of rail track the important task was to compare cross profiles with planned data. Figure 10 demonstrates an example of a created cross profile. White lines show the profile created in the point cloud, whereas red ones - planned one. Longitudinal profiles of rail tracks were created on the basis of the Profile-M trolley trajectory points (Figure 11).

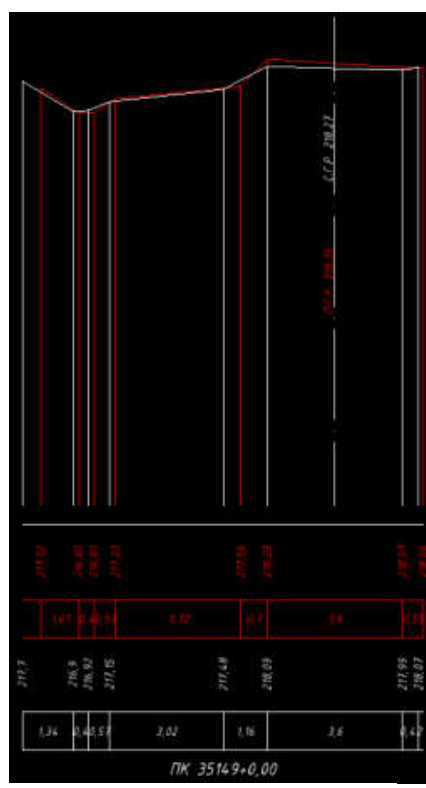

Figure 10. The example of a cross profile

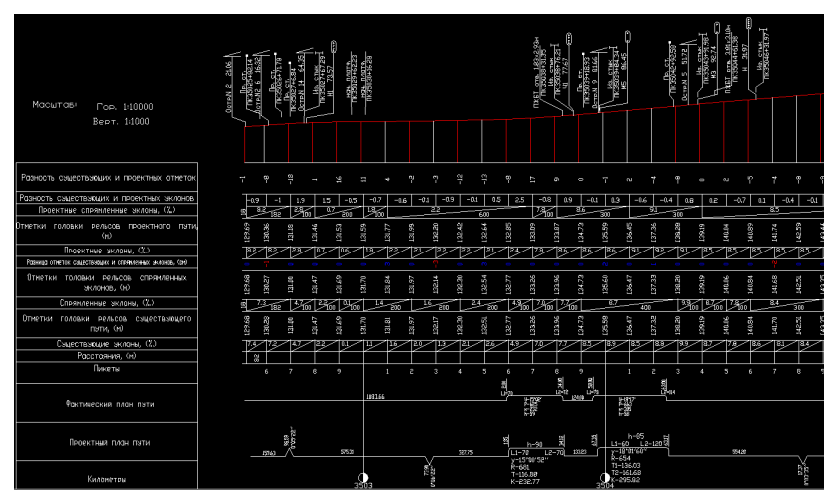

Figure 11. The example of a longitudinal profile

\section{CONCLUSION}

Data obtained with the Profile-M trolley and UAVs can be used for all stages of the railway as-built survey. If the Profile-M trolley allows measuring absolute position of rails, calculating their geometric parameters and creating longitudinal profiles, UAVs are applied for mapping of railway stations and stationto-station blocks, measuring obstruction clearance, distances between tracks, generating cross profiles. The trajectory recorded with the Profile-M trolley allows excluding creating vertical and horizontal control survey network when processing UAV images. Accuracy estimation results of generating photogrammetric models using UAV images showed that the Profile-M trolley should be moved along 2 adjacent rail tracks. If along the first track it is necessary to stop at all marking pegs to measure control point coordinates, along the second track it should be done at the beginning and at the end of a straight area part are only needed.

\section{REFERENCES}

Akturk, E., Altunel, A. O., 2019. Accuracy assesment of a lowcost UAV derived digital elevation model (DEM) in a highly broken and vegetated terrain. Measurement: Journal of the International Measurement Confederation, 136, 382-386. doi.org/10.1016/j.measurement.2018.12.101. 
Chen, P., Wu, Y., Qin, Y., Yang, H., Huang, Y., 2020. Rail fastener defect inspection based on UAV images: A comparative study. Proceedings of the 4th International Conference on Electrical and Information Technologies for Rail Transportation (EITRT) 2019, Lecture Notes in Electrical Engineering 640. doi.org/10.1007/978-981-15-2914-6_65.

Chen, Q., Niu, X., Zuo, L., Zhang, T., Xiao, F., Liu, Y., Liu, J., 2018. A railway track geometry measuring trolley system based on aided INS. Sensors, 18(2), 538. doi.org/10.3390/s18020538.

COPTRZ, 2018. DJI Phantom 4 vs DJI Phantom 4 RTK. https://www.coptrz.com/dji-phantom-4-vs-dji-phantom-4-rtk/ (20 January 2020).

Flammini F., Pragliola C., Smarra G., 2016. Railway infrastructure monitoring by drones. International Conference on Electrical Systems for Aircraft, Railway, Ship Propulsion and Road Vehicles \& International Transportation Electrification Conference (ESARS-ITEC). doi.org/10.1109/esars-itec.2016.7841398.

JCS "Russian Railways", 2013. Technical specifications for work on the reconstruction (modernization) and repair of the railway track, approved by Order of Russian Railways No. 75r. https://www.tdesant.ru/info/item/43 (20 January 2020). (in Russian).

JCS "Russian Railways", 2008. Methodological guidelines for the creating scale plans of railway stations. TSPT-54/26. https://www.tdesant.ru/info/item/65 (20 January 2020). (in Russian).

Jwa, Y., Sonh, G., 2015, Kalman Filter Based Railway Tracking from Mobile Lidar Data. ISPRS Ann. Photogramm. Remote. Sens. Spat. Inf. Sci., II-3/W5, 159-164. doi.org/ 10.5194/isprsannals-II-3-W5-159-2015.

Martínez-Carricondo, P., Agüera-Vega, F., Carvajal-Ramírez, F., Mesas-Carrascosa, F.-J., García-Ferrer, A., Pérez-Porras, F.J., 2018. Assessment of UAV-photogrammetric mapping accuracy based on variation of ground control points. International Journal of Applied Earth Observation and Geoinformation, 72, 1-10. doi.org/10.1016/j.jag.2018.05.015.

Mian, O., Lutes, J., Lipa, G., Hutton, J. J., Gavelle, E., Borghini, S., 2016. Accuracy assessment of direct georeferencing for photogrammetric applications on small unmanned aerial platforms. International Archives of the Photogrammetry, Remote Sensing and Spatial Information Sciences - ISPRS Archives, 40(3W4), 77-83. doi.org/10.5194/isprsarchives-XL-3-W4-77-2016.

Rosnell, T., Honkavaara, E., 2012. Point cloud generation from aerial image data acquired by a quadrocopter type micro unmanned aerial vehicle and a digital still camera. Sensors, 12(1), 453-480. doi.org/10.3390/s120100453.

Sahebdivani, S., Arefi, H., Maboudi, M., 2020. Rail track detection and projection-based 3D modeling from UAV point cloud. Sensors, 20(18), 1-15. doi.org/10.3390/s20185220.

Schenk, T., 2005. Introduction to Photogrammetry. Department of Civil and Environmental Engineering and Geodetic Science The Ohio State University.
Shcherbakov, I.V., 2017. Profile-M hardware and software suite for determining the spatial and geometric parameters of the track gauge. Vestnik SSUGiT, 22(3), 60-71 (in Russian).

Syetiawan, A., Gularso, H., Kusnadi, G. I., Pramudita, G. N., 2020. Precise topographic mapping using direct georeferencing in UAV. IOP Conference Series: Earth and Environmental Science, 500(1). doi.org/10.1088/1755-1315/500/1/012029.

Taddia, Y., Stecchi, F., Pellegrinelli, A., 2019. Using DJI Phantom 4 RTK drone for topographic mapping of coastal areas. The International Archives of the Photogrammetry, Remote Sensing and Spatial Information Sciences - ISPRS Archives, 42(2/W13), 625-630. doi.org/10.5194/isprs-archivesXLII-2-W13-625-2019

The British Standards Institution, 2019. Railway applications Track - Track geometry quality. Part 1: Characterization of track geometry. BS EN 13848-1:2019. BSI Standards Limited, UK.

Tong, L., Jia, L., Wang, Z., Wu, Y., Wang, N., 2020. Research on the segmentation and extraction of scenes along railway lines based on remote sensing images of UAVs. Proceedings of the 4th International Conference on Electrical and Information Technologies for Rail Transportation (EITRT) 2019, Lecture Notes in Electrical Engineering 639. doi.org/10.1007/978-98115-2866-8_47. 